\title{
En los ancianos el colesterol elevado también aumenta la mortalidad por enfermedad coronaria
}

Chiara Corti M, Guralnik J, Salive M et al. Clarifying the Direct Relation between Total Cholesterol Levels and Death from coronary Heart Disease in Older Persons. Ann Intern Med. 1997;126: 753-760

\section{Objetivo}

Determinar si la falta de relación aparente entre colesterol total $(\mathrm{CT})$ y riesgo de muerte por coronariopatía en ancianos puede explicarse por la presencia de comorbilidad.

\begin{tabular}{|c|c|c|c|c|}
\hline 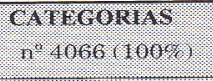 & 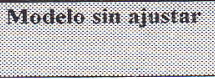 & 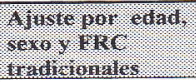 & 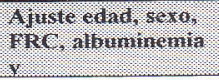 & $\begin{array}{l}\text { Aw we tortall } \\
\text { excluyendio eventos } \\
\text { ler ano }\end{array}$ \\
\hline 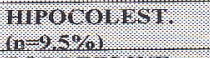 & $\begin{array}{c}\text { RR } 1.63 \\
\text { (95\% IC 1.09.2.64) } \\
\end{array}$ & NS & NS & NS \\
\hline 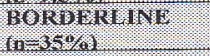 & NS & NS & NS & $\begin{array}{c}\mathrm{RR} 1.45 \\
(95 \% \text { IC } 1: 02-2.08)\end{array}$ \\
\hline 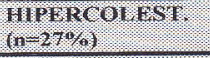 & NS & NS & $\begin{array}{c}\text { RR } 1.45 \\
(95 \% \text { IC } 1.06-2.10) \\
\end{array}$ & $\begin{array}{c}\text { RR } 1.57 \\
\text { (95\% IC_1.06-2.34) } \\
\end{array}$ \\
\hline MIII: $>35 \mathrm{rng} / \%$ & RR 2.52* & RR $1.90^{*}$ & RR 1.73* & RR 2.17* \\
\hline $11101.36 .59 \mathrm{mg} \%$ & NS & NS & NS & NS \\
\hline UDL $2.60 \mathrm{nng} / \%$ & NS & NS & NS & NS \\
\hline
\end{tabular}

La tasa cruda de eventos coronarios fatales fue mayor en hipocolesterolémicos. Después de ajustar por edad, sexo y factores de riesgo coronario tradicionales, el RR se volvió no significativo para hipocolesterolémicos y aumentó para los borderline e hipercolesterolémicos. Ajustando para marcadores inespecíficos de salud (sideremia y albuminemia), los hipercolesterolémicos tenían un incremento de riesgo de muer-

\section{Comentario}

El CT como predictor de mortalidad por coronariapatía ha sido cuestionado en ancianos (1). Varios trabajos encontraron una relación inversa colesterolriesgo de muerte $(2,3)$ o no encontraron relación $(4,5)$. Esto llama la atención dado que como con la edad aumenta la incidencia de enfermedad coronaria, cabría esperar una mayor asociación positiva entre CT y muerte por coronariopatía. En este contexto es atractiva la idea de la existencia de otros factores que estuvieran encubriendo y hasta invirtiendo la relación colesterol-muerte por coronariopatía (confundidores). La diferencia más obvia entre adultos de mediana edad y ancianos es la comorbilidad. Este estudio mostró que los pacientes con mayor deterioro asociado a hipocolesterolemia tuvieron menor sobrevida que aquellos más saludables aún con bajos niveles de colesterol. De ahi que el ajuste por indicadores inespecíficos pero sensibles de comorbilidad (hipoalbuminemia, sideropenia) depura la verdadera relación entre CT y morbi-

\section{Diseño}

Estudio prospectivo multicéntrico de cohortes.

Lugar

3 estados de EE.UU.

\section{Participantes}

4066 hombres y mujeres $\geq 65$ años seguidos anualmente con entrevistas desde 1988 hasta 1992.

Evaluación de Factores de Riesgo

Se evaluó hábitos de salud, condiciones crónicas y hospitalizaciones, CT, HDL, albúmina y sideremia. te coronaria estadísticamente significativo. Niveles de HDL bajos ( $<35 \mathrm{mg} \%$ ) se asociaron a un incremento del riesmente de los ajustes. La tasa cruda de muertes no coronarias en el primer año fue significativamente mayor entre hipocolesterolémicos y menor en hipercolesterolémicos. En el modelo ajustado no hubo asociación entre colesterolemia total y muertes no coronarias $(\mathrm{P}>0.2)$ go de muerte coronaria independiente-

Medición de Resultados Principales

Clasificación de participantes en 4 categorías: hipocolesterolémicos $(\leq 160$ mg\%), normocolesterolémicos (161-199 $\mathrm{mg} \%)$, borderline $(200-239 \mathrm{mg} \%)$ e hipercolesterolémicos ( $\geq 240 \mathrm{mg} \%)$. Según HDL : < $35 \mathrm{mg} \%, 35-59 \mathrm{mg} \%$ y > 60 $\mathrm{mg} \%$. Datos sobre HTA, diabetes o vasculares, alcohol y tabaco.

Resultados Principales

Se produjeron 252 muertes coronarias, 44 de ellas en el primer año.

\section{RIESGOS RELATIVOS (RR) DE MUERTE POR CORONARIOPATIA DE LAS DISTINTAS CATEGORIAS DE PERFILES LIPIDICOS EN COMPARACION CON PACIENTES NORMOCOLESTEROLEMICOS TASAS CRUDAS Y AJUSTADAS}

ni entre hipocolesterolemia y muerte no coronaria comparado con normocolesterolémicos (RR, 0.9 [IC, 0.82 a 1.34]).

\section{Conclusiones}

La hipercolesterolemia es un factor de riesgo para muerte por coronariopatía en los ancianos, y el aparente deterioro pronóstico asociado con niveles bajos de colesterol sería debido a comorbilidades.

mortalidad coronaria. Aquí hubo una clara asociación entre hipocolesterolemia y los marcadores de pobre estatus de salud. La exclusión de los eventos del primer año de seguimiento es otra forma de controlar el pobre estado de salud como factor de riesgo, que a su vez puede alterar secundariamente la variable en estudio (colesterolemia). No está claro si la comorbilidad simplemente enmascara el efecto del CT elevado por muchos años y descendido secundariamente hacia el final de la vida, o es factor de ries go independiente. Este estudio sugiere que la hipercolesterolemia es tan ries gosa en ancianos como en adultos, y que la hipocolesterolemia es un marcador de deterioro de salud y no un factor causal en los pacientes de peor pronóstico. Fal ta aún realizar estudios controlados para evaluar los efectos del tratamiento de la hipercolesterolemia en los ancianos y recomendar su rastreo sistemático. Al menos sabemos que la población blanco deberían ser los pacientes añosos con baja comorbilidad.
Dr. Alejandro Regueiro S.P.M Sistema de Protección Médica

\section{Referencias}

1. Hulley SB, Neuman TB. Cholesterol in the elderly. Is it important? (Editorial). JAMA 1994; $272: 1372-4$

2. Anderson KM, Castelli WP, Levy D. Cholesterol and mortality. 30 years of follow up from the Framingham study. JAMA 1987; 257: 2176-80.

3. Staessen J, Amery A, Birkenhager W y col. Is a high serum cholesterol level associated with longer survival in elderly hipertensives? J Hypertens. 1990; 8: 755-61.

4. Kronmal RA, Cain KC, Ye Z y col. Total serum cholesterol levels and mortality risk as a function of age. Areport based on the Framingham data. Arch Int Med. 1993; 153: 1065-73.

5. Krumholz HM, Seeman TE, Merril SS y col.Lack of association between cholesterol and coronary heart disease mortality and morbidity and all-cause mortality in persons older than 70 years. JAMA 1994; 272: 1335-40 